Discurso de derecha y resistencia frente al cambio constitucional. Análisis multimodal de un caso de propaganda electoral

Mauricio Esteban Alarcón Silva, Carolina Andrea Godoy Berthet

Question/Cuestión, Vol. 2, N 66, Agosto 2020

ISSNe 1669-6581

https://perio.unlp.edu.ar/ojs/index.php/question/index

IICom-FPyCS-UNLP

DOI: https//doi.org/10.24215/16696581e487

\section{Discurso de derecha y resistencia frente al cambio constitucional}

\section{Análisis multimodal de un caso de propaganda electoral Right-wing spee}

Right-wing speech and resistance against the constitutional change Multimodal analysis of an electoral propaganda case

\section{Mauricio Esteban Alarcón Silva}

mauricio.alarconsilva@gmail.com

https://orcid.org/0000-0002-7234-0392

Sociólogo, Magíster en Desarrollo Humano Local y Regional, estudiante del programa de Doctorado en Comunicación UFRO-UACH. Áreas de investigación: análisis de discurso, desarrollo y movimientos sociales. 


\section{Carolina Andrea Godoy Berthet}

c.godoy11@ufromail.cl

https://orcid.org/0000-0003-3460-0250

Socióloga, magíster en Desarrollo Humano Local y Regional, doctora @ en Ciencias Sociales. Áreas de investigación: alimentación, medios de comunicación, cuerpo y mujer. Núcleo científico y Tecnológico de Ciencias Sociales y Humanidades; Universidad de La Frontera

\section{Resumen}

En medio del estallido social, Chile logra un acuerdo político que determina una consulta ciudadana para decidir sobre el cambio de constitución vigente desde la dictadura militar. La consulta, fijada inicialmente para el 26 de abril de 2020 , encuentra al país en una polarización ideológica sustentada en la posible afectación a los pilares del modelo neoliberal, su constitución.

El presente trabajo aborda el discurso de derecha a partir de un caso de propaganda electoral a favor de la opción Rechazo el cambio. Analiza el discurso en su dimensión ideológica, también aborda recursos multimodales que son analizados mediante semiótica visual y metáfora multimodal.

Se evidencia la construcción de un nosotros (Rechazo) que valora el orden y la capacidad de elegir y soñar un país, que se distancia de un otros que engaña sobre una posible mayoría que se manifiesta en las calles. A través de elementos metafóricos apela a la amenaza de un enemigo con intenciones ocultas, representando a los políticos que usufructúan sin mayor esfuerzo de la democracia, en definitiva, tras el llamado a votar rechazo, un discurso 
coherente con las descripciones teóricas, que junto con restar valor a la participación, construye ideológicamente un enemigo al que se debe temer.

\section{Palabras clave}

Análisis de discurso, Análisis multimodal, cognición social, Comunicación política, discurso de derecha.

\section{Abstract}

In the midst of the social outbreak, Chile achieved a political agreement that determined a citizen consultation to decide on the change of constitution in force since the military dictatorship. The consultation, initially set for April 26, 2020, finds the country in an ideological polarization based on the possible impact on the neoliberal model pillar, its constitution.

This work addresses the right-wing discourse based on an election propaganda case in favor of the option I reject the change. It analyzes the discourse in its ideological dimension, also addresses multimodal resources that are analyzed through visual semiotics and multimodal metaphor.

It is evident the construction of an us (Rejection) that values order and the ability to choose and dream a country, distancing itself from an others who deceive about a possible majority that manifests in the streets. Through metaphorical elements, it appeals to the threat of an enemy with hidden intentions, representing politicians who use democracy without much effort, in short, after the call to vote rejection, a speech consistent with theoretical descriptions, which together with detracting from participation, ideologically builds an enemy to be feared. 


\section{Key words}

Discourse analysis, Multimodal analysis, social cognition, Political communication, right-wing discourse.

\section{Contexto Sociopolítico, Estallido social y cambio constitucional.}

El estallido social en Chile iniciado el 18 de octubre de 2019 dio lugar a múltiples reacciones en el mundo político interpelado. Desde el poder legislativo se oyeron voces expresando la necesidad de cambios inmediatos, por otro lado, aunque en menor medida, otro grupo de parlamentarios llamó a contener la protesta social mediante mecanismos coercitivos. Como un intento por dar salida política a la situación, el gobierno junto a los partidos oficialistas, con parte de la oposición logran el 15 de noviembre de 2019 el denominado acuerdo nacional por la paz y nueva constitución que establece mecanismos para lo que algunos catalogaron como "la madre de todas las batallas", esto es el cambio de la carta fundamental, vigente desde el año 1980 y redactada en plena dictadura cívico militar; la cual establece los pilares de un modelo neoliberal, cuyo impacto a nivel de la subjetividad social ha llegado al punto de «penetrar corazones y almas y de construir una figura subjetiva que pueda funcionar dentro de los dispositivos del capitalismo contemporáneo» (Fagoli, 2018, p.574), bajo estos cimientos se estabiliza un discurso hegemónico que normaliza la desigualdad y abusos generados en el contexto de las posibilidades normativas que el libre mercado establece.

A pesar de no existir un consenso social respecto a la forma y fondo de la medida para buscar un cambio constitucional, Chile se enfrenta por primera vez desde el retorno a la democracia el año 1990, ante la posibilidad de decidir 
sobre las bases normativas y estructurales del modelo de sociedad que desea vivir.

Más allá de las críticas procedimentales, los ciudadanos y el estallido social, han posicionado a nivel político un cuestionamiento profundo al modelo de sociedad, cuya matriz cultural ha sido impregnada con valores propios del neoliberalismo (Araujo, 2017). El mecanismo de decisión un plebiscito, que propone dos preguntas: ¿Quiere usted una nueva Constitución? Las alternativas serán: Apruebo o Rechazo. ¿Qué tipo de órgano debiera redactar la nueva Constitución? Las opciones: Convención Mixta Constitucional (asamblea conformada en un $50 \%$ por constituyentes o ciudadanos elegidos directamente y $50 \%$ por miembros del actual Congreso) o Convención Constitucional (asamblea conformada por $100 \%$ de constituyentes o ciudadanos elegidos).

A medida que se acerca la fecha del plebiscito, como era esperable, se aprecia una polarización del discurso ideológico, tanto en la opción de Apruebo el cambio de Constitución, como en la opción Rechazo.

El presente trabajo focaliza un caso de propaganda electoral que promueve el voto de Rechazo el cambio constitucional, cuya plataforma es la página web www.votarechazo.cl, esto a partir de análisis de discurso que aborda los diversos recursos semióticos utilizados en la propaganda, el procedimiento analítico contempla un enfoque sociocognitivo que incluye una dimensión ideológica, semiótica visual y análisis metáfora multimodal.

\section{Contexto comunicativo}

El plebiscito surge como respuesta al estallido social, por tanto, la participación de movimientos sociales que dieron vida a dicho estallido son parte importante 
en la promoción de la opción Apruebo. Así también también los partidos políticos de centro izquierda, opositores del gobierno asumen un rol fundamental en la coordinación de comandos electorales para promover el cambio constitucional.

Por otro lado, los partidos oficialistas de derecha, aunque en un inicio con algunas contradicciones, han sido parte de la organización de los comandos electorales que promueven la opción Rechazo, surgiendo además una serie de colectivos independientes pro derecha que han formado sus propios comandos electorales.

La fecha del plebiscito fue fijado inicialmente ${ }^{i}$ para el domingo 26 de abril de 2020, la legislación chilena establece que la propaganda electoral debe ser desde el día 60 antes del plebiscito hasta el tercer día anterior al plebiscito, esto es, entre el 26 de febrero y el 23 de abril de 2020. Sin embargo, previo a esa fecha, ya circulaba en la web una propaganda electoral, el sitio www.votarechazo.cl, amparado en un vacío legal que impide al Servicio Electoral inspeccionar a un privado que desea hacer campaña online, en este caso una agencia de publicidad que gestiona el dominio y el proyecto propagandístico en cuestión, tanto en la web como en otras redes sociales, instancia donde el colectivo que da origen a la web votarechazo se autodefine como una «Agrupación que informa, coordina y promueve la opción del rechazo al cambio constitucional en el plebiscito del 26 de abril de 2020» ii , los documentos del corpus corresponde a esta agrupación. Desde ese rol de enunciador participan del debate político, con estrategias discursivas que buscan reposicionar la opción de mantener el modelo político y económico de la Constitución elaborada hace 40 años en la dictadura cívico militar de la derecha. 


\section{Comunicación política, discurso e ideología}

La circulación de discursos asociadas a la actividad política en el contexto de una sociedad democrática, permite poner en juego la capacidad de entendimiento comunicativo en permanente tensión entre el poder, el conflicto, la estabilidad y el cambio social. Expresa un género discursivo particular, que nutre la investigación y análisis de diversas disciplinas que confluyen en el campo de la comunicación política.

Ahora, la efectividad del discurso político, radica en gran medida de las «representaciones semánticas que definen el "significado" de las proposiciones» (Van Dijk, 2003) que componen tal discurso. Esto es por un lado, el conocimiento sociocultural compartido por un grupo (common ground), así como las creencias que éstos comparten (que incluyen los criterios para dar por verdad un tipo de conocimiento). En tal sentido, el discurso como práctica social supone un componente cognitivo, que está a la base de su propia estructura discursiva y de las formas de interacción en la sociedad; dicho esto, la especificidad del discurso político, estaría dado por la mediación de este conjunto de creencias compartidas situadas en el ámbito de la cognición social, esto es la ideología «[...] que define la identidad de un grupo y, por consiguiente, los sentimientos subjetivos de la identidad social (pertinencia de sus miembros)»(Van Dijk, 2003, p. 28).

Tal como señala Van Dijk (2005) la ideología no aborda cualquier tipo de creencias o conocimientos compartidos, sino más bien aquellas más fundamentales o axiomáticas a partir de las cuales se da coherencia al actuar cotidiano, mediante adhesiones actitudinales u opiniones, por ejemplo respecto al origen de la vida, al rol del hombre o la mujer en la sociedad, o como el caso del presente estudio, el modelo económico o de sociedad más adecuado. 
Como una forma de organizar la estructura del discurso ideológico Van Dijk (2003) propone un esquema básico asociado a la identidad del grupo; esto es los «criterios de pertinencia, actividades, objetivos, normas, relaciones con los demás, recursos» (P.57)

Una manifestación comunicativa específica propia de la comunicación política es la propaganda; «que tiene como principal objetivo difundir ideas filosóficas, religiosas, políticas y sociales, vale decir opera en el ámbito ideológico» (Araya, 2016, p.19) discursivamente se mueve en un terreno de «imperativos categóricos [...] algo que no discute: o lo aceptas o te autoexcluyes» (Méndiz Noguero, 2007, p. 57). A diferencia de la publicidad (que busca seducir desde la lógica del consumo), la propaganda busca influir ideológicamente mediante discursos originados desde el poder político. Araya finalmente concluye una distinción difusa, reflexionando sobre la confluencia de publicidad y propaganda en el contexto de un modelo económico neoliberal.

\section{Discurso ideológico de derecha}

El discurso de derecha y derecha extrema ha sido ampliamente estudiado en Europa (Por ejemplo Wodak, 2015; Coffe, 2008; Kocze, 2018; Padovani, 2016; Shaw, 2019), así como en Latinoamérica y Chile (Por ejemplo Farre, J. 2017; Muñoz-Navarro, 2008; Bohoslavsky, 2012; Correa Sutil, 2005), a continuación una breve revisión de algunos elementos que permiten caracterizar la estructura del discurso ideológico de la derecha.

Para Wodak (2015), el discurso de derecha enfatiza una variedad de temas en la política cotidiana con los cuales construyen su identidad y buscan adhesión; desde alardes ambivalentes con pasados fascistas, percepción de amenazas a identidad nacional por parte de grupos étnicos y migrantes extranjeros hasta 
agendas conservadoras - cristiana. Estas distinciones analíticas realizadas por la autora concluyen con la afirmación de dos características centrales de los partidos populistas de derecha; esto es la política del miedo, valiéndose de la instrumentalización de algún grupo (étnico/minoría política/migrante, entre otros) «como chivo expiatorio para la mayoría de los problemas actuales, sino de todos, y posteriormente interpretar al grupo respectivo como peligroso y una amenaza para "nosotros" nación» (p.2). Y la arrogancia de la ignorancia donde se «apela al sentido común y al antiintelecualismo» (p.2).

En coherencia con lo anterior, las estrategias discursivas de la derecha se orientan a procesos de legitimación de su acción y propuestas políticas (van Leeuwen y Wodak, 1999), basándose para esto en dos elementos fundamentales, la evaluación moral referida a sistema de valores y la legitimación lograda por pequeñas historias o fragmentos de estructuras narrativas sobre el pasado o el futuro potencial (por ejemplo la referencia a el regreso al socialismo), narrativas reforzadas mediante metáforas que vinculan su temporalidad con la espacialidad geopolítica de administraciones políticas opuestas ideológicamente a la derecha y cargadas de connotación negativa (por ejemplo referencias al modelo cubano o venezolano).

Para el caso Chileno, Farre (2017) destaca la influencia del discurso de la ultraderecha en la conformación del lenguaje de la derecha, en el núcleo del modelo institucional y socioeconómico del Chile actual, evidenciando la forma en que los lenguajes hegemónicos de la derecha se han investido bajo marcos retóricos e ideológicos de la extrema derecha. Correa Sutil (2005) si bien no profundiza en las estructuras discursivas de la derecha chilena, a partir de un análisis histórico de ésta, analiza el surgimiento de la nueva derecha, surgida en la dictadura militar a partir de la elaboración de la constitución de 1980, 
sustentada en una democracia protegida que resguarda sus intereses (diversificados en diversos ámbitos de la economía) y que garantiza su preservación en la vida política democrática postdictadura.

Las estrategias argumentativas anticomunistas, constituyen otro componente esencial en el discurso de derecha en Chile, desde una perspectiva histórica esto es abordado por Bohoslasky (2012) quien plantea diversas posturas anticomunistas, desde un acento en la ineficiencia de las empresas públicas, dificultad del ejercicio de libertad multipartidaria, otras posturas relativas al vacío moral generado por el ateísmo comunista, hasta posturas vinculadas a la Doctrina de la Seguridad Nacional, viendo en la izquierda comunista como promotora de la lucha de clases a través de la violencia. Con diversas variantes estas posturas se mantienen vigentes en parte del pensamiento de derecha.

\section{Análisis de Discurso multimodal}

La comunicación humana es inherentemente multimodal, utiliza diverso modos semióticos. Bajo esta premisa el Análisis de Discurso Multimodal (ADM) constituye un nuevo enfoque en el campo de los estudios del discurso que «amplía el estudio del lenguaje per se al estudio del lenguaje en combinación con otros recursos tales como las imágenes, el simbolismo científico, la gestualidad, las acciones, la música y el sonido» (O' Halloran, 2012 p. 75), esta ampliación da lugar a un complejo sistema de creación de significados asociados a la resemiotización de estos recursos a medida que estos se despliegan en la praxis social. En tal sentido, «el ADM se ocupa de la teoría y del análisis de los recursos semióticos y de las expansiones semánticas que tienen lugar a medida que, en los fenómenos multimodales, se combinan las diferentes opciones semióticas disponibles». (O' Halloran. 2012, p.77). 
Asumir el discurso desde una mirada multimodal por tanto, implica una especial atención a la interacción de recursos semióticos diversos, esto es la creación de significado a partir de la combinación intermodal por ejemplo del texto y la imagen, esto es la intersemiosis (Jewitt, 2009).

Desde una dimensión sociocognitiva, el presente trabajo aborda el discurso multimodal considerando las posibilidades que ofrece la teoría de la metafora conceptual de Lakoff y Johnson (1986), quien entiende «la metáfora no es solamente una cuestión de lenguaje, es decir, de palabras meramente. Sostenemos que, por el contrario, los procesos de pensamiento humano son en gran medida metafóricos» (Lakoff y Johnson, 1986 p.38). A partir de esta premisa Forceville (2009) profundiza en las caracaterísticas de la metafora multimodal, en particular aquellos dominios representados a través de recursos semioticos distintos al verbal. Así, en el análisis del discurso multimodal la metafora, como un recurso cognitivo de uso frecuente en la interacción social, permite entender un fenómeno abstracto (dominio meta) en términos de otro fenómeno mas concreto (dominio fuente).

\section{Semiótica visual}

La polisemia de la imagen tal como señala Joly (2009) se caracteriza por la ausencia de focalización asertiva, esto es la capacidad de poner de relieve los elementos del enunciado (no verbal) a través de medios propios al código utilizado «la imagen habla poco de ella misma» (p. 95), no afirma ni niega, eso que en el lenguaje verbal es fácilmente percibido. En tal sentido el lenguaje escrito puede contribuir en el procedimiento que utiliza la imagen para poner de relieve alguna parte del enunciado icónico, complementando aspectos como el color, el encuadre, la composición, la iluminación, etc. 
Un aporte interesante en esta línea es el desarrollado por el Groupe $\mu$ (1992), que desde una semiotica visual cognitiva, analiza la noción de signo icónico, unidad visual, que en tanto forma de representación permite reconocer ciertos objetos del mundo pero que, dada su naturaleza semiotiotica, deja en evidencia que no es el objeto, estableciendo de esta forma un vínculo entre el significado y la experiencia sensorial.

La noción de signo icónico contribuye a enteder la segmentación de mensajes de la imagen «permitió aislar unidades figurativas que constituyen una gran parte de la mayoría de los mensajes visules» (Joly, 2009, p. 115)

En forma complementaria el Groupe $\mu$ asigna a la noción de signo plastico, un estatus de signo en plenitud, distinguiendo dos tipos descritos por Joly (2009), los no específicos de los mensajes visuales que corresponde a «aquellos que remiten directamente a la experiencia perceptiva [...] como los colores, la iluminación o la textura» (p. 120); aquellos específicos de la representación visual «como el marco, el encuadre o la pose del modelo» (p.120).

\section{Corpus y procedimiento metodológico}

El corpus se configura a partir de un Análisis de caso correspondiente a los contenidos de página web www.votarechazo.cl, el cual presenta por un lado un texto breve denominado La causa y en segundo término un conjunto de seis diseños bimodales (fotografía: imagen y texto), usados para transmitir mensajes propios del genero afiche de propaganda política. Luego dos caricaturas acompañadas por breves textos.

Respecto al primer documento, el recurso semiótico textual (monomodal) contiene la declaración de principios, el fundamento del mensaje que se pretende entregar en la acción de propaganda, que a su vez proporciona 
significados de base para interpretar los siguientes documentos bimodales. Respecto de dicho texto, se procede al siguiente procedimiento analítico:

- Análisis sociocognitivo del discurso, contemplando para ello la dimensión ideológica, esto a partir de la estructura discursiva ideológica propuestas por Van Dijk (2003) y posteriormente operativizada por Camila Cárdenas (2016) a través de las siguientes categorías; Polarización, Descripción, Identificación, Intereses, Actividad, Normas y Valores.

Respecto del segundo grupo de documentos, en primer término seis afiches de propaganda electoral, fotografías con un breve texto y dos imágenes, caricaturas, con textos que forman parte de la imagen, se procede a un análisis de discurso multimodal (texto - imagen); que alterna la integración de dos enfoques teóricos;

- Semiótica visual (Groupe $\mu$ ); Análisis de discurso (mensaje visual) a partir de signos plásticos; Color, iluminación, textura, marco y el encuadre.

- Análisis de metáfora multimodal (Forceville, 1996).

\section{Análisis}

Análisis discurso ideológico, texto la causa: El breve texto La Causa, expuesto en la página principal de la página web www.votarechazo.cl, contiene los principios guía del enunciador; el argumento central los que queremos vivir en el Chile que soñamos un primer elemento en busca de identificación ¿Quién se puede querer excluir de querer vivir en el lugar soñado? Respecto de este sujeto se representan y emplazan las acciones: 


\section{LA CAUSA}

Con confianza y optimismo te podemos contar que cada día somos más los que estamos uniendo voluntades para decir: Rechazo.

No estás solo, es lo que te han hecho creer, pero no es verdad; somos muchos en esta causa.

De a poco vamos despertando y no nos vamos a someter al miedo que nos tratan de imponer. Esta vez, nuestra voz se va a escuchar más fuerte que nunca. Hay que resolver las Urgencias Sociales; cambiar la Constitución no es prioridad, la podemos reformar en paz. Súmate a esta cruzada. Porque cada corazón, cada persona y cada voto cuenta.

Vamos que juntos podemos

¡Somos más los que queremos vivir en el Chile que soñamos!

Texto: La Causa (Fuente: www.votarechazo.cl)

La dimensión ideológica muestra primeramente la polarización de distintos bandos en disputa, la conformación de un endogrupo basado en la idea de una mayoría por la opción Rechazo que existe en potencia, que se estaría gestando a partir de los atributos positivos que lo constituyen, un endogrupo que despierta frente a la opción Apruebo, esto es un otro cargado de atributos negativos pero que hasta ahora se ha posicionado mediáticamente como la opción más fuerte.

En tal sentido, la Descripción se observa en los criterios para la conformación del endogrupo, basada en la representación negativa del exogrupo, que por un lado engaña, haciendo creer que en términos de cantidad son pocos los que adhieren a la opción Rechazo y por otro lado infunden temor, esto en alusión a 
la fuera mediática mostrada por la movilización social en torno a la opción Apruebo.

Respecto de la Identificación, esto es la conformación de una identidad grupal que vincula los criterios más estables de pertenencia; sin asumirse explícitamente como minoría, la metáfora estamos despertando lo reconoce, pues asume un rol tardío y pasivo previo al inicio de la campaña (y durante el estallido social), sin embargo es una minoría que está o debe dejar ese estado para asumir un rol activo y constituir una mayoría que se preocupa de lo concreto, lo urgente.

En los Intereses; se evidencia el fundamento del propósito, es un llamado a adherir a una opción particular, esto es el Rechazo al cambio constitucional.

La Actividad reconocida socialmente es el llamado a realizar en concreto el acto de votar por el rechazo del cambio de constitución.

En el mensaje se aprecia una posición valórica/normativa frente el cambio social; por una lado cambios no estructurales (urgentes), que apelan a un conocimiento y valoración previa del estado de la demanda social en curso, frente a la asociación del cambio constitucional con la violencia, pues si bien se indica podemos reformar en paz, se presupone en el texto que la manera en que los otros pretenden reformar no es en paz, por tanto, el exogrupo pretendería una reforma violenta.

Así también, al señalar que Somos más los que queremos vivir en el Chile que soñamos se desprende una implicatura referida a una minoría (que aprueba el cambio constitucional) que quiere vivir en un Chile, que no responde a sueños propios, es decir, la idea de un modelo impuesto externamente.

Puesto que el discurso ideológico se centra en diferenciar entre un nosotros y ellos, se aprecia la intención de mostrar un nosotros dotado de dinamismo, de 
proyección, de futuro; (Cada día somos más, Somos muchos en esta causas, de a poco vamos despertando, esta vez nuestra voz se va a escuchar). El otro, en cambio te ha hecho creer, engaña e infunde miedo

Frente a la necesidad de ser creíble, el grupo emisor requiere presentar evidencias que prueben en un debate ideológico lo que afirman; si bien, dicha función se aprecia en la estructura discursiva del caso analizado, ésta más bien constituye una apelación a elementos emocionales y actitudinales Con confianza y optimismo te podemos contar que cada día somos más", la apelación es a la activación de un conocimiento contextual impuesto en los medios de comunicación (dominado por el propio conglomerado de derecha) que da cuenta de un aumento progresivo de la opción Rechazo en encuestas de opinión.

Al respecto durante los primeros meses de la movilización social en Chile, fue evidente la existencia de una demanda por el cambio de Constitución (la evidencia principal de esta afirmación es el acuerdo político consistente en el plebiscito que abre la posibilidad a dicho cambio). El movimiento social fue capaz de posicionar dicha demanda y exponer masivamente las consecuencias sociales de las características del modelo económico neoliberal vigente en el país. Frente a este escenario de descontento social generalizado, resulta difícil para la derecha proponer sin más, mantener la constitución que ampara dicho modelo, por lo que se recurre a estrategias de ambigüedad y mitigación discursiva, como Hay urgencias que resolver, Cambiar la constitución no es prioridad, la podemos reformar en paz, con eso, en apariencia no niega la necesidad de cambiar la constitución, sin embargo es más urgente abordar otros problemas (problemas que se suponen conocidos y ampliamente difundidos en el marco de la movilización social), y dado que cambiar la 
constitución implica violencia, optemos por abordar los problemas prioritarios vía reformas no estructurales.

\section{Análisis discurso visual y relieves textuales; afiches de propaganda (fotografías)}

Las imágenes (fotografías) presentadas como afiche de propaganda política, más allá de presentar una amplia diversidad tipológica (jóvenes, adultos, hombres mujeres, adulto mayor), apelan al conocimiento contextual, en la representación de un hombre o mujer común, que cumple con el estereotipo de un electorado de clase media chilena, aquejada por las problemáticas levantadas como demanda en el movimiento social, estudiantes, dueñas de casa, pensionados, trabajadores, en fin, una búsqueda por identificar un potencial elector, en la incertidumbre representada en la soledad del personaje fotografiado e inseguridad frente a un futuro que se ve sombrío.

Los colores, son absorbidos por el juego de iluminación y sombras. El reflejo luminoso que dota en cada caso un único color a la imagen central (rostro) refuerza la idea de diversidad, no sólo en términos tipológicos sino también ideológicos.

En su trayecto, la direccionalidad luminosa frontal destaca el relieve, para luego intentar atravesar el secreto de las sombras, entorno misterioso, incierto, inseguro y desconocido. Lo conocido e iluminado es el territorio de la certeza. Por el contrario «la oscuridad alimenta los temores y supersticiones» (Joly, 2009, pág. 123)

La iluminación del rostro permite destacar las texturas de éste, "sensualiza" con un llamado no sólo a la vista, sino a acercarse a ella, a tocar la imagen, en definitiva a sentir una necesidad de cercanía. 


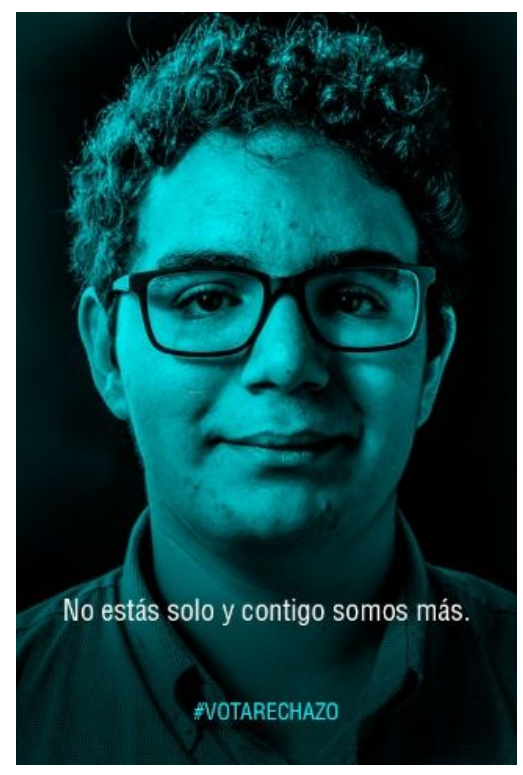

Imagen $\mathrm{N}^{\circ}$ 1: hombre joven

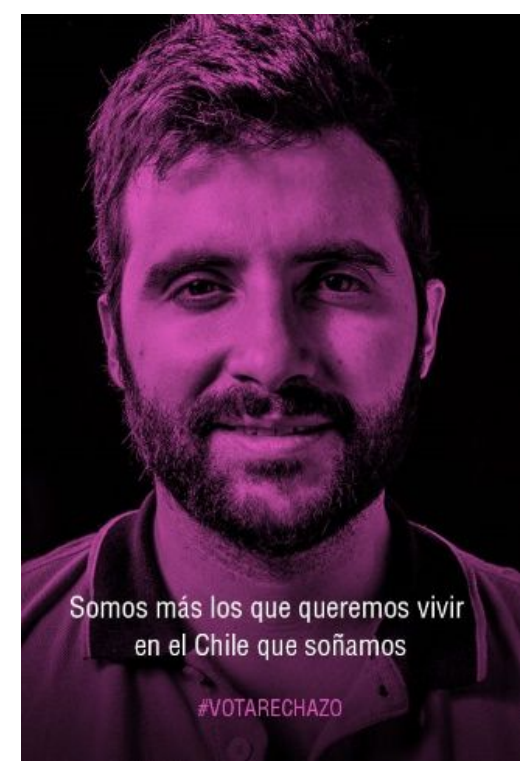

Imagen $\mathrm{N}^{\circ} 2$ : hombre adulto 
(fuente www.votarechazo.cl)

Las imágenes muestran una iluminación artificial, lo que permite acentuar el sentido de una realidad alternativa o posible, relacionada con una atemporalidad más propicia a la duda o a un sueño (en oposición al realismo que supone una iluminación natural), este rasgo es complementado en textos que proponen la posibilidad de una realidad que no es, Vamos que juntos podemos. Súmate a esta cruzada (Imagen $\mathrm{N}^{\circ} 3$ ), la implicatura es que solos, como la imagen representada, no se puede lograr en forma exitosa el triunfo de la opción Rechazo el cambio de constitución. Por tanto, en la situación real, están solos, si te sumas a la cruzada es posible una realidad distinta (ganar el plebiscito). No estás solo y contigo somos más (Imagen $\mathrm{N}^{\circ} 1$ ), la implicatura, tú crees que estás sólo o te han hecho creer que estas solo, por tanto, además de asumir la situación de engaño, si te sumas y acomáñas la opción del rechazo, serán más (realidad posible). Ahora, la apelación a una realidad posible no sólo se refiere al escenario de ser mayoría sino a una mayoría con expectativas particulares Somos más los que queremos vivir en el Chile que soñamos

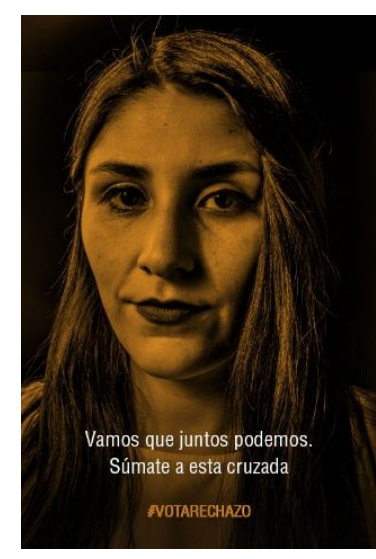

Imagen $\mathrm{N}^{\circ}$ 3: mujer adulta 


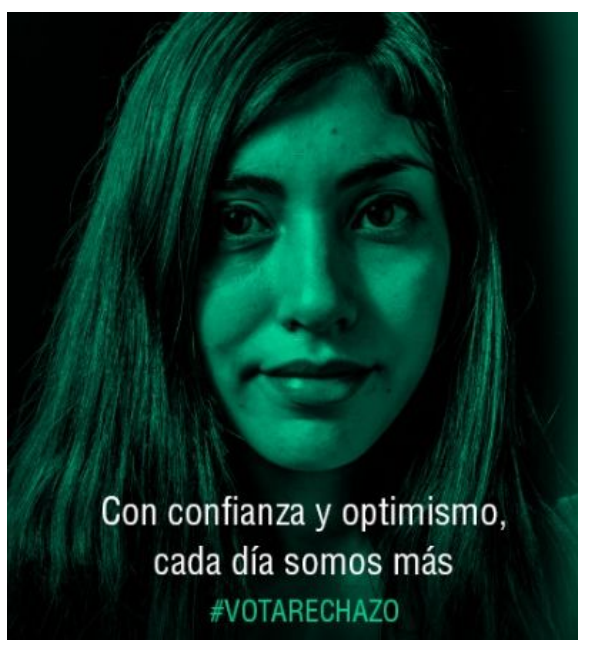

Imagen $\mathrm{N}^{\circ}$ 4: mujer jóven

(fuente www.votarechazo.cl)

El borde de la imagen, carente de un marco genera un efecto de olvido del carácter representacional de la imagen «se la presenta ya no como un enunciado visual, una interpretación, sino una vez mas como el mundo mismo» (Joly, 2009, p.129), así, el marco difuminado se olvida y confunde con los límites de la imagen central (el rostro), delimitando el campo visual, generando una tensión; por un lado la impresión de que al ampliar el marco de la imagen, sería posible observar que hay mas allá del rostro, esto es un límite que actúa como una ventana sobre la cual podríamos introducir la mirada, así, de forma imaginaria completamos el campo representado, sin embargo por otro lado, eso potencialmente observable se mantinene en las oscuridad, hay algo mas allá pero está oculto en las sombras. 


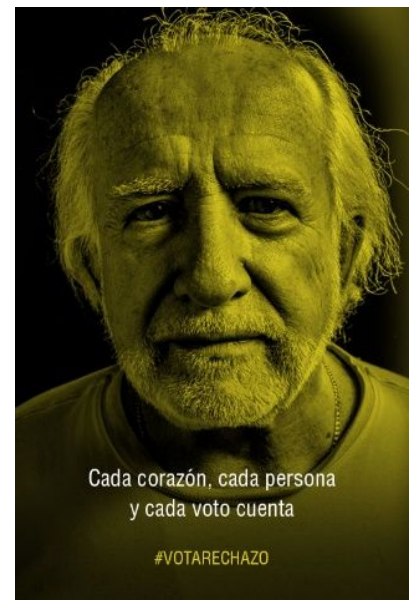

Imagen $\mathrm{N}^{\circ}$ 5: hombre adulto mayor

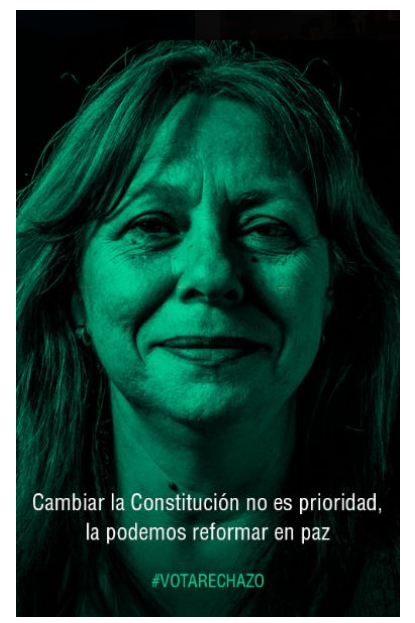

Imagen $\mathrm{N}^{\circ}$ 6: Mujer adulto mayor

(fuente www.votarechazo.cl)

El Encuadre constituye uno de los elementos centrales para la interpretación del mensaje global, en cada caso corresponde a un primer plano, esto es la imagen de un rostro hasta los hombros, cuyo efecto, complementado con el texto que acompaña, busca generar el efecto de interacción personalizada, «este pseudo frente a frente elimina el espacio de la representación y establece una aparente relación interpersonal, una relación dual. Es un yo que se dirige a un tu, en una relación de superioriodad y de exhortación» (Joly, 2009, pag. 140). Es un frente a frente, mirando a los ojos, un juego de complicidad en una relación aquí y ahora.

\section{Análisis metafora multimodal}

Las caricaturas representadas en las siguientes imágenes se orientan a abordar la segunda pregunta del plebiscito, ¿Qué tipo de órgano debiera redactar la nueva Constitución? 


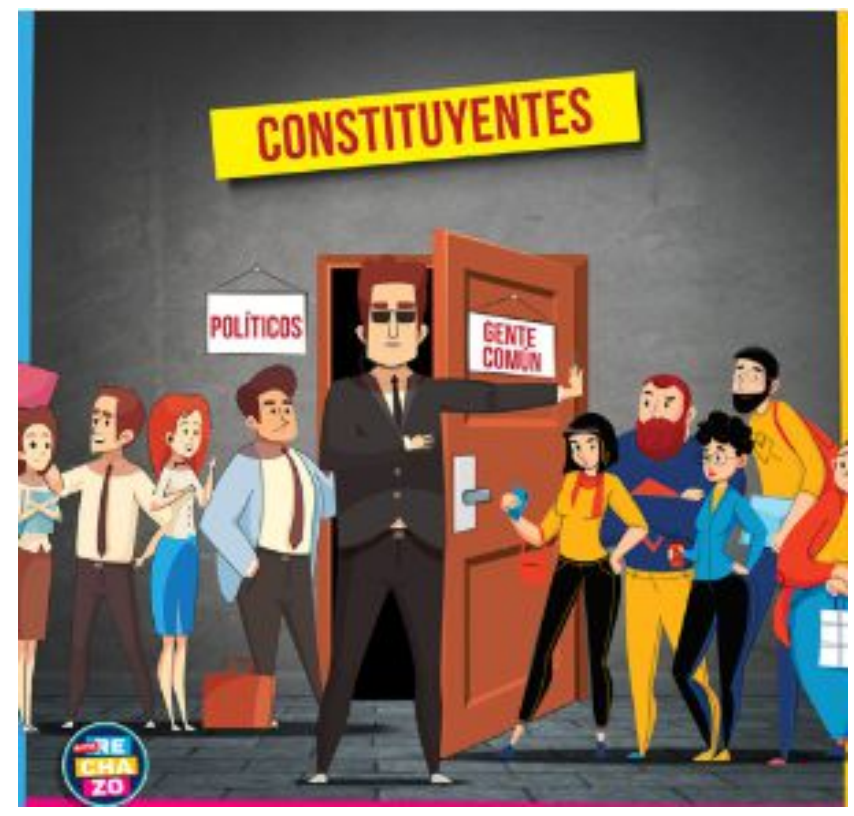

Imagen $\mathrm{N}^{\circ} 7$ Hombre de negro (fuente www.votarechazo.cl)

En la imagen $\mathrm{N}^{\circ} 7$, la propagada (caricatura) muestra a un personaje central, que posee el control de entrada a una sala, cuya puerta de acceso entre abierto posee la etiqueta Constituyentes. El dominio fuente evoca la figura de un Hombre de negro esto es un agente secreto, típico de series o comic norteamericanos (Comic The men in black del año 1990; Película Hombres de negro del año 1997, también personajes similares en Dark City, The Matrix, The $X$-files, entre otras), de carácter hosco y maluhumorado, perteneciente a alguna agencia de gobierno, que junto con proteger a la humanidad, le oculta al mundo los orígenes de posibles amenazas alienígenas o de otra especie. La figura muestra a este hombre de negro impidiendo con su mano el avance de un grupo de personas etiquetadas con la expresión Gente común, el cual es un cartel que está sobre la puerta cuya abertura, junto con la mano del Hombre de 
negro bloquean el ingreso a la sala Constituyentes. La gente común; dos hombres de barba y dos mujeres, de pelo color oscuro, con jeans o pantalones negros, perfil, que desde una mirada conservadora es asociado al estereotipo de la izquierda progresista, que contrasta con el grupo que en la imagen y gracias a la acción del agente secreto (Hombre de negro) tiene la posibilidad de entrar a la sala; la etiqueta de Políticos muestra a dos hombres vestidos formalmente con corbata y traje (uno de ellos ya con una mano dentro de la sala Constituyentes), y dos mujeres con pelo claro y falda, una imagen estereotipada del político conservador de derecha en Chile, el mensaje claro, los textos presentes en la imagen (Políticos, Constituyentes y Gente común, aportan como rol de anclaje para interpretar la metáfora del agente secreto, responsable de mantener un orden amenazado por fuerzas desconocidas para la mayoría, velando por el bien superior del país; la discusión constitucional no es para Gente común, más aún si esa gente común que espera entrar a la discusión, es de izquierda y con intereses misteriosos, en consecuencia, la discusión sobre el cambio constitucional debe quedar reservada para la elite política tradicional. El texto del logo de la campaña por el Rechazo en la parte inferior izquierda, permite comprender el sentido general del mensaje, aunque en apariencia muestra una incongruencia, se rechaza el cambio constitucional, pero frente a la posibilidad de un triunfo de la opción Apruebo, es preferible que en ésta participen los actuales congresistas.

La imagen $\mathrm{N}^{\circ} 8$ busca denostar al oponente político mediante una metafora que en apariencia es contradictoria con el mensaje anterior; pero que cobra sentido desde la contextualización histórica del discurso de la dercha chilena; contradictorio pues sitúa el ejercicio democrático de una opción política como mecanismo de enriqueimiento, por tanto el cuestionamiento es a la estructura 
democrática, en este sentido el texto Políticos de siempre como anclaje de la metafora de llevarse el dinero en una carretilla llena, aprovechandose de la democracia, muestra a estos políticos de siempre con el sólo esfuerzo de trasladar la carretilla, ese es su trabajo. Entonces la opción del rechazo, por antonomasia refuerza la idea de una sociedad donde el dinero y los privilegios asociados es fruto del trabajo (y no necesariamente de la estructura de oportunidades que la misma sociedad establece). Cabe destacar que quien deposita el dinero es un personaje del cual sólo vemos su mano y brazo, y se distingue en él que viste de traje, en esta ocasión el estereotipo del político formal, que si bien representa al pueblo, vota apruebo para seguir reproduciendo esta lógica de aprovechaiento económico de la democracia.

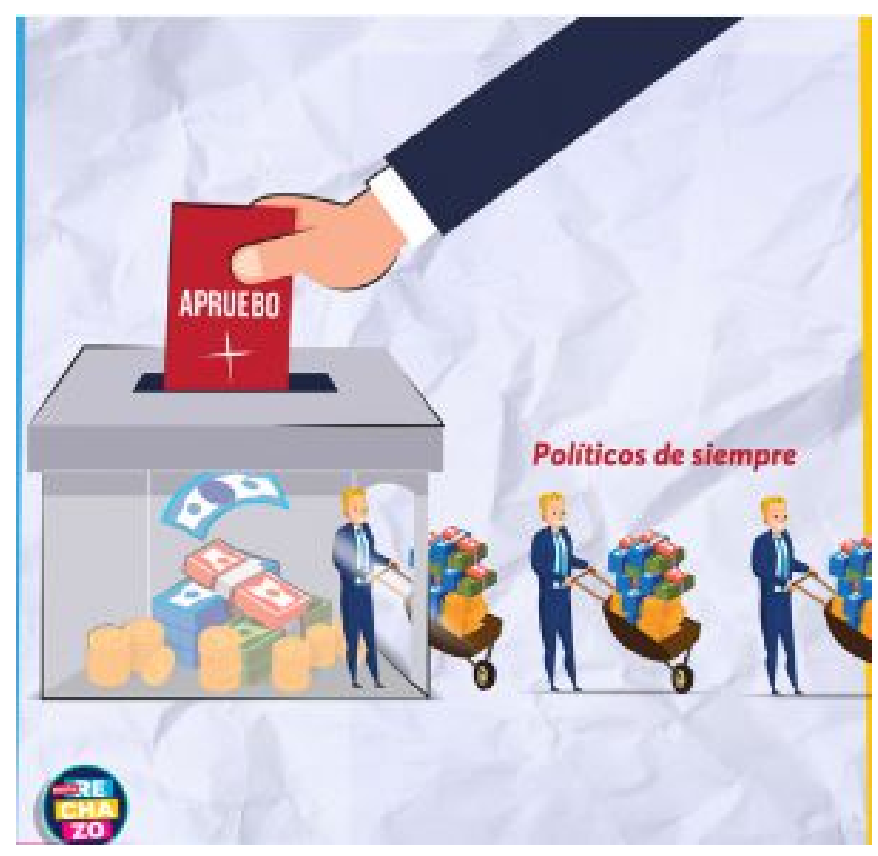

Imagen $\mathrm{N}^{\circ} 8$ Carretilla con dinero (fuente www.votarechazo.cl) 


\section{Consideraciones finales}

La estructura ideológica del discurso de la derecha chilena, en el marco de la campaña por el rechazo se radicaliza a medida que se acerca el momento del plebiscito, cargada de elementos contextuales asociados al estallido social, que junto con posicionar mediaticamente la necesidad de cambios estructurales, logró incorporar en la agenda pública un procedimiento para dichos cambios. Frente a ese escenario el inicio de la contienda política se da desde la desventaja para la opción del Rechazo (en términos de adhesión electoral), por tanto el despliegue discursivo utilizado por la derecha se orientan a revertir ese punto de partida desfavorable, apelando a elementos cognitivos y contextuales que permiten dar sentido a los principales recursos semioticos que estructuran tradicionalmente las campañas electorales de la derecha chilena; la construcción de otro que se ha visto fuerte en el estallido social, pero que no representa valores de estabilidad y orden que cada ciudadano del país quiere (en terminos individuales y desde la perspectiva de un nosotros ideológico), por el contrario se apela al miedo frente a quienes quieren un cambio radical, pues ese cambio es guiado por un enemigo peligroso y amenazante como diría Wodak (2015), la formula simple, apelando al sentido común (siguiendo a la misma autora) Somos más, Sólo debes sumarte... con confianza y optimismo.

La liberatd económica que sustenta el modelo económico amparado en la constitución de 1980 se extrapola a otras formas de libertad, como valor supremo, nos permite concretar nuestros sueños, esa libertad es sinonimo de la estabilidad que proporciona el modela actual, por tanto cualquier atisbo de cambio, desde el discurso de derecha, es adentrarse en un mundo de incertidumbres, oscuro y peligroso, como las imágenes que rodean los rostros de la propaganda electoral. 
El mensaje claro es el llamado a votar por el rechazo, ahora es evidente cierta ambigüedad en el discurso, el cual probablemente se vincula al procedimiento mismo del acto eleccionario definido en el acuerdo por la paz del 15 de noviembre, esto en referencia a las preguntas sobre las cuales se debe decidir; por un lado ¿Quiere usted una nueva Constitución?, los dos primeros documentos del corpus aluden con claridad la opción del rechazo; sin embargo la segunda pregunta del plebiscito ¿Qué tipo de órgano debiera redactar la nueva Constitución? Asume la posibilidad del triunfo de la opción Apruebo, por tanto la campaña debe tener una segunda línea propagandística que se basa en la derrota frente a la primera pregunta; dado que puede ganar la opción Apruebo, ahora veamos que alternativa es más conveniente para cambiar la constitución; Convención Mixta Constitucional (asamblea conformada en un $50 \%$ por constituyentes elegidos directamente y $50 \%$ por miembros del actual Congreso) o Convención Constitucional (asamblea conformada por 100\% de constituyentes elegidos). Acá se juega con dicha ambigüedad, la opción de la derecha es convención mixta, incluyendo a congresistas (políticos) en la discusión para definir una nueva constitución y no sólo ciudadanos elegidos para tal efecto, la estrategia nuevamente es simple, el anticomunismo, siendo el chivo expiatorio la izquierda en general y las narrativas asociadas a las experiencias de asamblea constituyente asociada fundamentalmente a Venezuela, es la línea argumentativa en los diversos recursos semióticos desplegados en la propaganda, asociados al violentismo y al enriquecimiento sin esfuerzo. 


\section{Bibliografía}

- Araujo, Kathya. (2017). Sujeto y neoliberalismo en Chile: rechazos y apegos. Nuevo Mundo Mundos nuevos. https://doi.org/10.4000/nuevomundo.70649

- Araya, C. (2016). Análisis crítico de tres afiches de la campaña contra la violencia hacia la mujer: Maricón es el que maltrata a una mujer. Contextos, 25, 13-28.

- Bohoslavsky, E. (2012). ¿Qué es lo nuevo de la nueva derecha en Chile? Anticomunismo, corporativismo y neoliberalismo, 1964-1973. História Unisinos, 16 (1), 5-14.

- Cárdenas, C. (2018). Discurso de protesta y redes sociales. Análisis de las prácticas discursivas activistas producidas en la comunidad de Facebook Universitario Informado durante las movilizaciones estudiantiles en Chile (20112013). Tesis Doctoral Universidad Pompeu Fabra.

- Coffe, H. (2008). (Small) enterpreneurs first! Analysis of the economic discourse of Vlaams Belang. Journal of Language and Politics, 7(1), 31-52.

- Correa Sutil, S. (2005). Con las riendas del poder. La derecha chilena en el siglo $X X$. Santiago de Chile: Sudamericana.

- Fagioli, A. (2018). Acumulación originaria y capitalismo neoliberal. Una posible lectura del Chile post-golpe. Isegoria, 59, 573-593. https://doi.org/https://doi.org/10.3989/isegoria.2018.059.11

- Farre, J. (2017). The rhetoric of the extreme in the Chilean far right. HallazgosRevista de Invesitigaciones, 14(27), 19-41.

- Forceville, C. (2017. Metaphor in Pictures and Multimodal Representations. En J. Raymond W. Gibbs (Ed.), The Cambridge Handbook of Metaphor and Thougt (January 2008, pp. 462-482). Cambridge University Press. 
- Groupe $\mu$ (1992) Tratado del signo visual. Para una retórica de la imagen, Editorial Le Seuil, París, 1992; Madrid, Cátedra

- Jewitt, C. (2009a). 'An Introduction to Multimodality', en C. Jewitt (ed.) The Routledge Handbook of Multimodal Analysis, pp. 14-27. London and New York: Routledge.

- Joly, M. (2009) La imagen fija. Buenos Aires. Ediciones la cuadrícula.

- Kocze, A. (2018). Race, migration and neoliberalism: distorted notions of Romani migration in European public discourses. Social Identities, 24(4), 459473.

- Lakoff, G. y Johnson, M. (1986), Metáforas de la vida cotidiana, Madrid: Cátedra.

- Méndiz Noguero, A. (2007). Diferencias conceptuales entre publicidad y propaganda: una aproximación etimológica. Questiones Publicitarias, 12, 43. https://doi.org/10.5565/rev/qp.122

- Muñoz-Navarro, A. (2008). La nación en el discurso de la derecha. Un análisis ideológico del debate parlamentario chileno. Signo y Pensamiento, vol. XXVII, núm. 53, pp. 174-192 Pontificia Universidad Javeriana Bogotá, Colombia

- O'halloran, K. L. (2012). Análisis del discurso multimodal. Revista Latinoamericana de Estudios del Discurso, 12(1), 75. https://doi.org/10.35956/v.12.n1.2012.p.75-97

- Padovani, C. (2016). The media of the ultra-right Discourse and audience activism online. Journal of Language and Politics, 15(4), 399-421.

- Shaw, D. (2019). Something Old, Something New, Something Borrowed: the Alt-Right on Building Christendom Without Christ. Journal for the Study of Religions and Ideologies, 18(54), 79-92. 
- Van Dijk, T. (2003). Ideología y Discurso. Una introducción multidisciplinaria. Barcelona. Editorial Ariel.

(2005) Ideología y análisis del discurso. Utopía y Praxis

Latinoamericana, vol. 10, núm. 29, abril-junio, 2005, pp. 9-36 Universidad del Zulia Maracaibo, Venezuela

- Van Leeuwen, T., \& Wodak, R. (1999). Legitimizing immigration control: A discourse-historical analysis. Discourse Studies, 1(1), 83-118. https://doi.org/10.1177/1461445699001001005

- Wodak, R. (2015). The Politics of fear. What right-wing populist discourses mean. Los Angeles, London, New Delhi, Singapore, Washington DC: Sage.

\section{Notas}

' Debido a la emergencia sanitaria y medidas derivadas de la pandemia por el Covid-19, el plebiscito se postergó para el 25 de octubre de 2020.

i En cuenta de instagram vota_rechazo hace referencia a sitio web votarechazo.cl 